\title{
Induction of pancreatic tumours by longterm duodenogastric reflux
}

\author{
P R TAYLOR, R H DOWLING, T J PALMER, D C HANLEY, G M MURPHY, \\ R C MASON, AND I MCCOLL
}

From the Departments of Surgery, Gastroenterology and Pathology, UMDS, Guy's Hospital, London

SUMmARY The incidence of pancreatic cancer is increased in patients who have undergone gastric surgery. An animal model is described in which pancreatic hyperplasia and adenoma formation developed within 56 weeks. The effects of a simple gastrojejunostomy were compared with those after a split gastrojejunostomy, in which the jejunum was transected and the two limbs implanted separately into the greater curvature of the glandular stomach $1 \mathrm{~cm}$ apart. After 56 weeks no animals in the simple gastrojejunostomy group had pancreatic hyperplasia whereas all 10 animals in the split gastrojejunostomy group had generalised pancreatic hyperplasia with macroscopic nodules. Microscopy of the nodules showed that in nine animals hyperplastic nodules had developed, and four of these also had adenomatous nodules. The remaining animal had enlarged lymph nodes. Pancreatic hyperplasia was associated with jejunal hyperplasia. Jejunal morphometry showed that the villus height was doubled and the villus height:crypt depth ratio was higher in the split gastrojejunostomy group compared with those animals with a simple gastrojejunostomy. This finding represents a new model for the investigation of pancreatic neoplastic change.

Recent epidemiological studies have shown an increased incidence of pancreatic cancer in patients who have undergone gastric surgery.' ' Until now, however, there has been no experimental model with which to study this association.

A major interest in our unit has been the investigation of gastric carcinoma using an animal model which does not require the presence of carcinogens. Langhans first described the induction of gastric adenocarcinomas by duodenogastric reflux in the rat without the use of carcinogens. ${ }^{3}$ We confirmed these findings, ${ }^{+}$and undertook further experiments to study the sequence of carcinogenesis. In order to determine the site of maximal histological change in the stomach, the two limbs of the gastrojejunostomy were divided and anastomosed separately to the stomach.

This operation of 'split' gastrojejunostomy was associated with pancreatic hyperplasia and nodule

Address for correspondence: Mr P R Taylor, FRCS. UMDS. (iuy`s Hospital. St Thomas Street. London SEI $9 R T$

Accepted for publication 6 March 1989 formation. These findings were fortuitous and significant because carcinogens were not used.

\section{Methods}

ANIMALS

Male Wistar rats weighing 200-250 g were randomised into two groups to undergo either a simple (conventional) gastrojejunostomy $(n=13)$ or a split gastrojejunostomy $(n=10)$.

All operations were performed at the same time of day to minimise any variations related to circadian rhythms. Anaesthesia was induced with $4 \%$ halothane in oxygen, and maintained by $1 \cdot 5-2 \%$ halothane in oxygen. Laparotomy was performed through an upper midline abdominal incision.

A simple gastrojejunostomy was performed by anastomosing a loop of jejunum, $4 \mathrm{~cm}$ distal to the ligament of Treitz, to the body of the stomach. To do this, a $7 \mathrm{~mm}$ gastrotomy was made $2 \mathrm{~mm}$ distal to the squamocolumnar junction along the anterior surface of the greater curvature. The jejunum was incised 


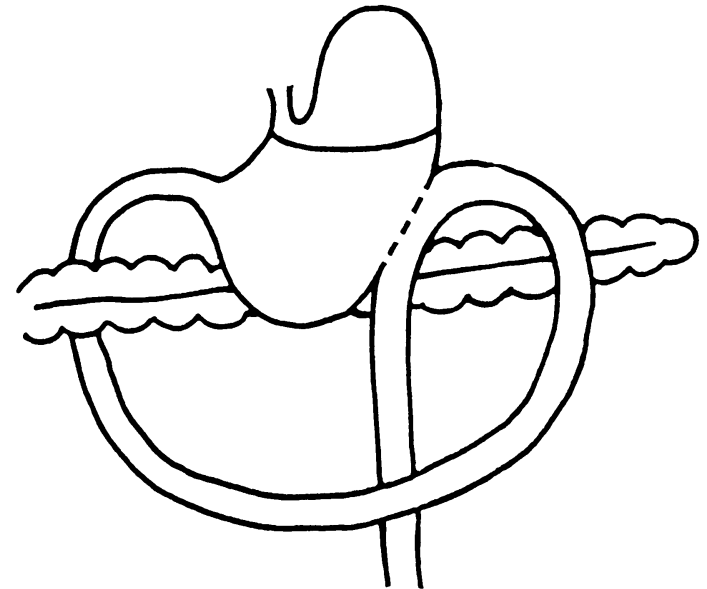

Fig. 1 Conventional antecolic isoperistaltic simple gastrojejunostomy.

along the antimesenteric border for $7 \mathrm{~mm}$ and an alllayer gastrojejunal anastomosis fashioned (Fig. 1).

In the split gastrojejunostomy group, the same loop of jejunum as that used in the simple gastrojejunal anastomosis, was transected and the afferent limb anastomosed to the glandular portion of the stomach, again $2 \mathrm{~mm}$ distal to the squamocolumnar function. The efferent limb was then anastomosed to the greater curvature $1 \mathrm{~cm}$ distal to the afferent anastomosis (Fig. 2). The gastrojejunal anastomoses were sutured with continuous all layer 6/0 Ethibond. At the end of the procedure, subcutaneous injections of $0 \cdot 15 \mathrm{M}$ saline $(10 \mathrm{ml})$ for hydration, and buprenor-

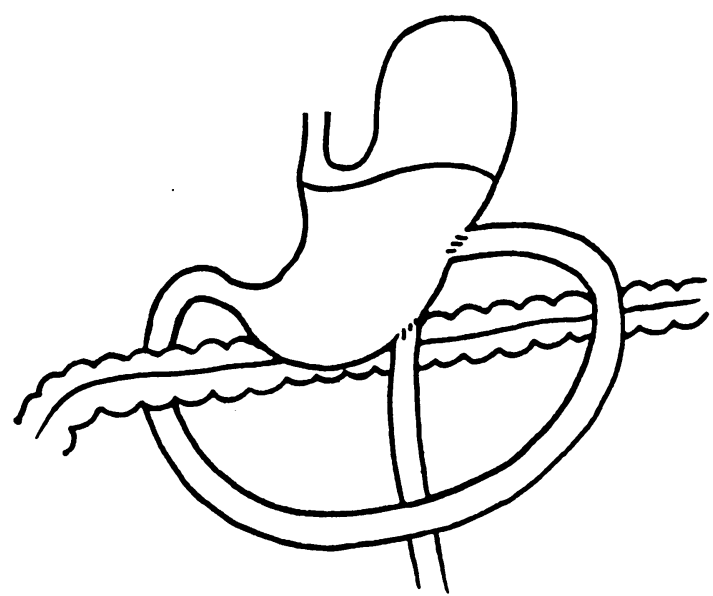

Fig. 2 Split gastrojejunostomy. The jejunum has been transected and the two limbs implanted into the stomach with separate anastomoses. phine $(30 \mu \mathrm{g} / 100 \mathrm{~g}$ body weight) to minimise postoperative discomfort, were given.

The animals were fed with no 1 rat and mouse maintenance diet (Scientific Diet Services, Stepfield, Essex), and were maintained under identical laboratory conditions.

Based on the results of previous studies, we anticipated that gastric carcinomas would develop from 32 weeks onwards in increasing numbers. We therefore killed the animals 56 weeks after the original operation. The animals were anaesthetised with $4 \%$ halothane in oxygen, and the stomach and the pancreas removed en bloc. The animals were then killed by exsanguination. The whole of the pancreas was dissected free from adjacent tissue, and fixed in formal saline for subsequent histological studies. Full thickness jejunal segments $(1-2 \mathrm{~cm})$ were also taken for morphometric analysis from the afferent limb, at least $0.5 \mathrm{~cm}$ away from the anastomosis (to avoid scar artifact). Seven serial sections, $3 \mu \mathrm{m}$ thick, were cut from each block of pancreatic tissue and stained with either haematoxylin and eosin or a combined Elastic Martius Scarlet Blue stain.' The presence of nodules was assessed according to published criteria." Hyperplastic nodules were arbitrarily defined as those which have no associated capsule, while adenomatous nodules were those which had a circumseribed fibrous capsule. Experiments with raw soy flour have established a sequence of hyperplastic nodules, adenomatous nodules and carcinomas occurring in the rat pancreas."

The height of the villi and depth of the erypts in the afferent jejunal limb were measured using a Leitz Wetzlar stage graticule with viewing tube. The ratio of villus height:crypt depth was calculated from these measurements.

STATISTICAL. ANAI,YSIS

The statistical significance of differences in values between the two groups was assessed by the Mann Whitney U test.

\section{Results}

MACROSCOPIC FINDINGS

At 56 weeks, although all the animals looked healthy, there was a significant difference in the body weights between the two groups. The split gastrojejunostomy group had a mean body weight of $495 \mathrm{~g}$ (SEM 23) and the simple gastrojejunostomy group 643 g (29); $\mathrm{p}<0 \cdot(05)$. At autopsy, the most noticeable difference was the greatly dilated afferent jejunal limb which was present in all the animals of the split gastrojejunostomy group (Fig. 3). This was associated in every case with hyperplasia and nodule formation in the pancreas (Fig. 4). 


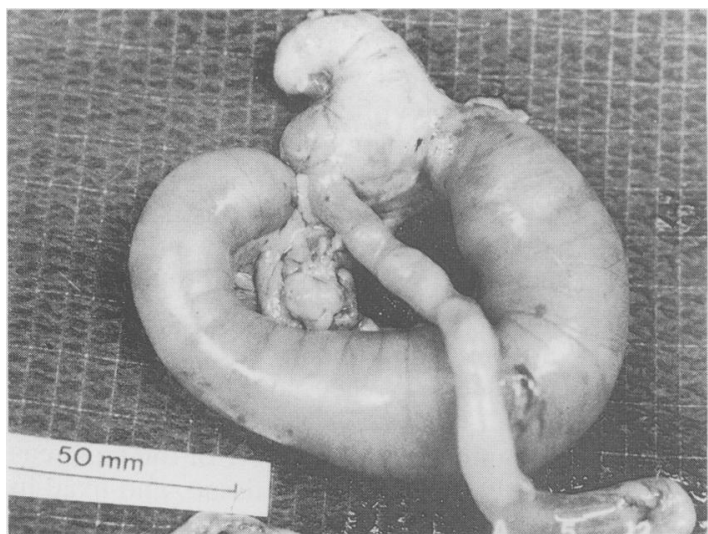

Fig. 3 Stomach of normal size is dwarfed by the large afferent jejunal limb of the split gastrojejunostomy.

In contrast, none of the animals in the simple gastrojcjunostomy group showed jejunal dilatation and none showed evidence of hyperplasia or nodule formation in the pancreas.

\section{MICROSCOPIC FINIINGS}

\section{Pancreas}

The results of the pancreatic microscopy are shown in Table 1. In one of the rats from the split gastrojejunostomy group, the pancreatic nodules contained only lymphoid tissue. In all nine remaining animals, however, hyperplastic nodules were present in the pancreas and in four, there were, in addition, adenomatous nodules. In the cells from the nodules, there was a definite increase in nuclear and nucleolar size with a much more open chromatin pattern than in cells from the adjacent pancreas. There was also variability in nuclear size and shape within the nodules and occasional binucleate cells were seen.

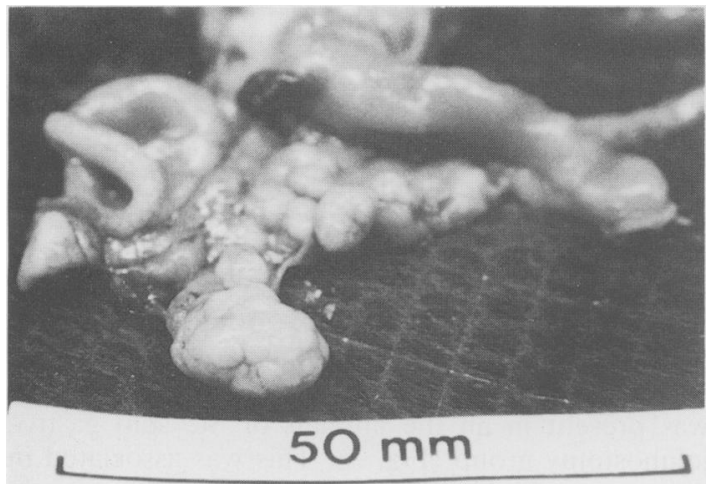

Fig. 4 Part of the head of the pancreas showing marked nodule formation.
Table 1 Microscopic pancreatic findings

\begin{tabular}{lllll}
\hline Group & $n$ & $\begin{array}{l}\text { Hyperplastic } \\
\text { nodules }\end{array}$ & $\begin{array}{l}\text { Adenomatous } \\
\text { nodules }\end{array}$ & $\begin{array}{l}\text { Lymph } \\
\text { nodes }\end{array}$ \\
\hline Simple & 13 & 0 & 0 & 0 \\
Split & 10 & 9 & 4 & 1 \\
\hline
\end{tabular}

Mitoses, although present, were not frequent. A striking feature of all nodules was the amount of apoptotic material present indicating increased cell turnover. In addition, many nodules showed increased eosinophilia of the zymogen granules. One of the nine animals showed extensive subacute pancreatitis, and, in another, the pancreas contained an inflammatory infiltrate around the neurovascular bundles which did not involve the secretory portion of the gland. None of the other animals showed any evidence of pancreatic duct obstruction. No rats showed evidence of in situ or invasive carcinoma.

\section{Jejunum}

The results of the histological studies in the jejunum are shown in Table 2. The mean villus height was increased by $104 \%$ in the split gastrojejunostomy group compared with the simple gastrojejunostomy animals. The ratio of villus height:crypt depth was more than doubled in the split gastrojejunostomy group.

\section{Discussion}

This paper describes a new model for the induction of pancreatic hyperplasia in the rat. This was achieved by separation of the limbs of a gastrojejunostomy using two independent anastomoses (split gastrojejunostomy). The development of pancreatic hyperplasia and adenoma formation was a fortuitous observation made during experiments designed to study the effect of duodenogastric reflux on the stomach.

No comparable studies have been reported but two other groups have separated the limbs of a gastrojejunostomy during experiments to study gastric carcinogenesis. ${ }^{7 \times}$ In both their reports, however, carcinogens were used to induce malignant change, and although the effects on the gastric mucosa were

Table 2 Microscopic jejunal morphometric findings

\begin{tabular}{llll}
\hline Group & $n$ & $\begin{array}{l}\text { Villus height } \\
\mu m(S E M)\end{array}$ & $\begin{array}{l}\text { Ratio of villus } \\
\text { height to crypt depth }\end{array}$ \\
\hline Simple & 13 & $460(12)^{*}$ & $1 \cdot 55: 1$ \\
Split & 10 & $940(19)^{*}$ & $3.65: 1$ \\
\hline
\end{tabular}

$* \mathrm{p}<() \cdot() 1$. 
described, there were no details of pancreatic pathology.

In the present study, we have described the effects of chronic duodenogastric reflux (DGR) on small bowel and pancreatic pathology, 56 weeks after operation. Although we used an appropriate surgical control group, we did not study unoperated rats. Given the fact that pancreas was normal in the conventional gastrojejunostomy group, however, and that there were striking differences in the pancreatic morphology between the two operated groups, the lack of an unoperated control group seems unimportant.

The mechanism for the pancreatic changes in the split gastrojejunostomy group is unknown. The dilated afferent loop in these animals was associated with pancreatic hyperplasia, but it is not certain that these two findings are causally related. The duodenum and upper jejunum are, however, the site of cholecystokinin (CCK) synthesis and release. Therefore one possible explanation is that hyperplasia of the duodenal and jejunal mucosa is associated with hyperplasia of the CCK secreting cells at these sites. If so, this might result in hypercholecystokininaemia which, in turn, produces pancreatic hyperplasia.

The results of three studies support this hypothesis. First, exogenous administration of CCK is known to cause pancreatic hyperplasia." Second, raw soy bean flour (a potent inhibitor of trypsin) stimulates pancreatic growth in the rat ${ }^{11}$ and is associated with hypercholecystokininaemia." Third, the operation of pancreaticobiliary diversion (PBD), in which the jejunum is interposed isoperistaltically between the pylorus and the ampulla of Vater, causes pancreatic hyperplasia and adenomatous nodule formation over 15 months. ${ }^{12}$ This is associated with an increase of cholecystokinin in the plasma. ${ }^{13}$

If the hypothesis that pancreatic hyperplasia is secondary to hyperplasia of the afferent and efferent loops is correct, the mechanism for this small bowel growth remains unknown. At first sight, the appearances of the afferent limb suggested obstruction and stagnation with bacterial overgrowth in the blind loop. Dissection of the loop and the anastomotic sites, however, showed no evidence of obstruction. Furthermore, studies of self-filling blind loops show that obstruction causes type 2 changes in the small bowel mucosa with hyperplastic crypts and stunted villi indicating an injury and repair process. Our results clearly show that this was not the pattern of mucosal change in the afferent loop of the split gastrojejunostomy group. Both the height of the villi and the ratio of villus height:crypt depth indicate an adaptive type 1 response. Other hormones such as enteroglucagon, epidermal growth factor and gastrin may be involved.
There are at least two different consequences on upper gastrointestinal physiology after the operations of simple gastrojejunostomy and split gastrojejunostomy. First, the split gastrojejunostomy requires complete transection of the jejunum which may disrupt the normal neuromuscular propulsive activity of the small bowel. Second, simple gastrojejunostomy may cause only partial reflux of duodenal contents into the stomach as some of the chyme may pass along the small bowel without entering the stomach. Conversely, duodenogastric reflux is obligatory in the split gastrojejunostomy group because all the duodenal contents must pass through the stomach.

Further experiments are being done to elucidate firstly, the precise mechanism of production of these pancreatic adenomas; secondly, the histological sequence with time to study the relationship of hyperplastic to adenomatous nodules, and finally the response of both the pancreatic and small bowel changes to reversal of the split gastrojejunostomy.

This work has been carried out as part of the requirement for the degree of $M$ Chir of the University of Cambridge.

\section{References}

I Caygill CPJ, Hill MJ, Hall CN, et al. Increased risk of cancer at multiple sites after gastric surgery for peptic ulcer. Gut 1987: 28: 924-8.

2 Mack T, Yu M, Hanisch R. Pancreas cancer and smoking, beverage consumption and past medical history. J Natl Cancer Inst 1986: 76: 49-60).

3 Langhans P. Heger R. Hohenstein J, et al. Operation sequel carcinoma of the stomach. Experimental studies of surgical techniques with or without resection. World J Surg 1981; 5: 595-605.

4 Mason RC. Duodenogastric reflux in rat gastric carcinoma. Br J Surg 1986; 73: 801-3.

5 Buk SJA. Simultaneous demonstration of connective tissue elastic and fibrin by a combined Verhocff's Elastica-Martius-Scarlet-Bluc trichome stain. Stain Technol 1984; 59: 1-5.

6 Levison DA, Morgan RGH, Brimacombe JS, et al. Carcinogenic effects of di(2-hydroxypropyl)nitrosamine (DHPH) in male Wistar rats: promotion of pancreatic cancer by soya flour diet. Scand J Gastroenterol 1979; 14: 217-24.

7 Kondo K. Suzuki H, Nagayo T. The influence of gastrojejunal anastomosis on gastric carcinogenesis in rats. Jpn J Cancer Res 1984; 75: 362-9.

8 Houghton PWJ, Mortensen NJMcC, Williamson RCN. Effect of duodenogastric reflux on gastric mucosal proliferation after gastric surgery. $B r$ J Surg 1987: 74: 288-91.

9 Rothman SS, Wells $H$. Enhancement of pancreatic enzyme synthesis by pancreozymin. Am J Physio 1967; 13: $215-8$. 
10 Folsch UR, Wormsley KG. Pancreatic secretion of enzymes in rats treated with soy bean diet. Scand $J$ Gastroenterol 1974; 9: 679-83.

11 Adrian TE, Pasquali C, Pescosta F, et al. Soya-induced pancreatic hypertrophy and rise of circulating cholecystokinin [Abstract]. Gut 1982: 23: A889.

12 Stace NH, Palmer TJ, Vaja S, et al. Long term pancreaticobiliary diversion stimulates hyperplastic and adenomatous nodules in the rat pancreas: a new model for spontancous tumour formation. Gut 1987; 28: (Suppl 1) 26.5-8.

13 Miazza BM, Levan H, Ghatci M. et al. Role of regulatory peptides in the small bowel and pancreatic adaptation of pancreatico-biliary diversion (PBD) following jejunal or ileal transposition in the rat. Eur $J$ Clin Invest 1982; 12: 1.57. 